\title{
The hydrogen molecule as antioxidant therapy: clinical application in hemodialysis and perspectives
}

\author{
Masaaki Nakayama ${ }^{1,2^{*}}$, Shigeru Kabayama ${ }^{2,3}$ and Sadayoshi Ito ${ }^{2,4}$
}

\begin{abstract}
Increased oxidative stress and pro-inflammatory conditions, commonly present in chronic dialysis patients, are thought to be enhanced during hemodialysis (HD) and to be associated with the excess morbidity and mortality seen in these patients. The hydrogen molecule $\left(\mathrm{H}_{2}\right)$ has a unique biological capacity to act as an antioxidative and anti-inflammatory substance. In light of accumulating evidence from animal studies showing protective effects against organ damage during ischemia and inflammation, development of $\mathrm{H}_{2}$ treatments for HD patients has become a challenging clinical goal.

An HD system utilizing a water electrolysis technique that renders large amounts of $\mathrm{H}_{2}$-enriched water has been developed. During HD with an $\mathrm{H}_{2}$-enriched solution (approximately $50 \mathrm{ppb} \mathrm{H}_{2}$ ), markers of increased oxidative stress (such as interleukin-6, myeloperoxidase, methemoglobin, increased lymphocyte apoptosis, and high blood pressure) are suppressed. These findings indicate that the use of an $\mathrm{H}_{2}$-enriched solution may prove to be a novel approach to ameliorate dialysis-related complications. This manuscript reviews the recent progress in $\mathrm{H}_{2}$ research and the use of $\mathrm{H}_{2}$ in $\mathrm{HD}$ patients, including a description of a water electrolysis technique that delivers large amounts of $\mathrm{H}_{2}$-enriched water for use in clinical settings.
\end{abstract}

Keywords: Molecular hydrogen, Oxidative stress, Hemodialysis, Electrolyzed water

\section{Background}

Enhanced oxidative stress and pro-inflammatory conditions are common in chronic dialysis patients and are thought to be associated with the excess morbidity and mortality of these patients [1-3]. Given concurrent underlying clinical conditions, multiple factors play a role in the pathology involved, such as uremic solute accumulation, which enhances the oxidative response [4], including indoxylsulfate [5]; accumulation of advanced glycation end products [6], AOPP [7], methylglyoxal [8, 9], and trans-aconitate [10]; excessive spontaneous respiratory neutrophil apoptosis $[11,12]$, which causes the release of myeloperoxidase (MPO) into the blood [13]; disturbed antioxidative systems occurring during progressive uremia, including decreased production of

\footnotetext{
*Correspondence: masanaka@fmu.ac.jp

'Department of Nephrology and Hypertension, Fukushima Medical

University, Hikarigaoka 1, Fukushima City 960-1295, Japan

${ }^{2}$ United Centers for Advanced Research and Translational Medicine, Center

for Advanced and Integrated Renal Science, Tohoku University, Sendai, Japan Full list of author information is available at the end of the article
}

hydrogen sulfide [14] and suppressed Nrf2 activation [15]; and activation of monocytes [16] with loss of antioxidative capacity [17] during the hemodialysis (HD) procedure. Therefore, the development of antioxidant therapies has been recognized as a high priority for dialysis patients. Currently available agents are limited to tocopherol [18-20] and $N$-acetylcysteine [7, 21], and evidence of their efficacy has not been established in the clinical setting.

Recently, it has been shown that the hydrogen molecule $\left(\mathrm{H}_{2}\right)$ has a unique biological capacity as an antioxidative and anti-inflammatory substance [22]. Evidence that $\mathrm{H}_{2}$ administration ameliorates organ damage in various models of ischemia and inflammation has been accumulating [23]. For this reason, clinical applications of $\mathrm{H}_{2}$ for pro-inflammatory disorders are under active investigation, particularly for use during HD therapy [24-29].

This manuscript reviews recent progress in $\mathrm{H}_{2}$ research and details the applicability of a water electrolysis 
technique with the capacity for delivering large amounts of $\mathrm{H}_{2}$-enriched water for the clinical HD setting.

\section{The hydrogen gas molecule as a biological antioxidant}

Biological effects of $\mathrm{H}_{2}$ and primary mechanism of its action In 2007, Ohsawa et al. [22] first reported that pretreatment with $\mathrm{H}_{2}$ inhalation ameliorated brain lesions after cerebral infarction in rats. Thereafter, accumulating evidence from animal studies indicated a protective effect of $\mathrm{H}_{2}$ pretreatment on the progression of organ damage in various types of disease models [30-69], such as ischemia-induced injury and dysfunction of the brain [22, 33, 39, 55, 59, 62-64], heart [34, 45, 59, 65], liver [30], retina [41], and kidney [59, 60]; stress-induced hippocampus dysfunction [38]; cisplatinum nephropathy [37, 44]; transplanted intestinal graft [31, 47]; corneal alkali burn [51]; ouabain-induced auditory neuropathy [66]; lung injury by oxygen toxicity [43, 46]; paraquat [52]; extensive burns [54]; chronic allograft nephropathy [48]; and radiation injuries in various organs $[49,50,55$, 68, 69]. In Parkinson's disease [36, 40] and Alzheimer's disease models [42], $\mathrm{H}_{2}$ ameliorates neurodegenerative changes in the brain. $\mathrm{H}_{2}$ suppresses development of hypertension in spontaneously hypertensive rats [67]. Furthermore, $\mathrm{H}_{2}$ acts on metabolic pathways to suppress the development of atherosclerosis in apolipoprotein $\mathrm{E}$ knockout mice [32] and diabetes in $\mathrm{db} / \mathrm{db}$ mice [53].

In previous studies, $\mathrm{H}_{2}$ was administered by inhalation $[22,30,31,34,37,45,46,56,62-64,66]$ or dissolved in water [22, 32-44, 47-55, 57-61, 65, 67-69]. Irrespective of the administration route, $\mathrm{H}_{2}$ pretreatment could suppress oxidation, inflammation, and apoptosis while enhancing antioxidant reactions in those models.

Thus far, the precise mechanisms of action involved in $\mathrm{H}_{2}$ protection from organ injury remain unclear, but it is thought that the $\mathrm{H}_{2}$ molecule, which freely diffuses into cells, can react with toxic radicals, such as excess superoxide anions $\left(\mathrm{O}_{2}^{-}\right)$generated in mitochondrial respiratory complexes and hydroxyl radical [22, 23, 70], according to the following reactions:

$$
\begin{aligned}
& \mathrm{O}_{2}^{-}+\mathrm{H}_{2} \rightarrow \mathrm{H}_{2} \mathrm{O}_{2}+\mathrm{e}^{-} \\
& \cdot \mathrm{OH}+\mathrm{H}_{2} \rightarrow \mathrm{H}_{2} \mathrm{O}+\cdot \mathrm{H}^{\circledR} \mathrm{H}_{2} \mathrm{O}+\mathrm{H}^{+}+\mathrm{e}
\end{aligned}
$$

Suppression of oxidative stress by $\mathrm{H}_{2}$ could lead to suppression of downstream signaling in pathways such as MAPK [48], MEK-1 [48], NFkB [71], caspase-3 [33, 39], and caspase-12 [33], which would decrease proinflammatory molecule production and apoptosis. This unique characteristic of $\mathrm{H}_{2}$ is thought to protect cells and organs from free radical injury. Figure 1 summarizes the molecular effect of $\mathrm{H}_{2}$ on oxidative stress, inflammation, and apoptosis.

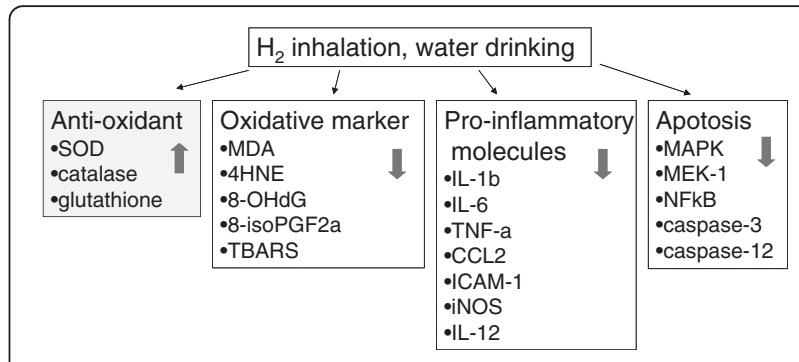

Fig. 1 Summary of the molecular effect of $\mathrm{H}_{2}$ on oxidative stress, inflammation, and apoptosis. Effects of $\mathrm{H}_{2}$ as an antioxidant and anti-inflammatory molecule are summarized. Accumulating evidence from animal studies has revealed that $\mathrm{H}_{2}$ is a biologically active gas, increasing antioxidative molecules, while decreasing oxidative markers, pro-inflammatory molecules, and apoptosis in affected organs and tissues

\section{Quantification of $\mathrm{H}_{2}$ amount needed to elicit biological effects}

By quantifying the amount of $\mathrm{H}_{2}$ administered in animal experiments, it is possible to speculate on the $\mathrm{H}_{2}$ dose needed for biological effects in vivo. From studies using $\mathrm{H}_{2}$-enriched drinking water $\left(0.3\right.$ to $\left.0.6 \mathrm{mM} \mathrm{H}_{2}\right)$, an effective $\mathrm{H}_{2}$ dose can be calculated roughly as the product of $\mathrm{H}_{2}$ concentration and amount of daily water intake. Given a model using 200-g animals and $20 \mathrm{ml}$ of enriched water intake daily, the $\mathrm{H}_{2}$ ingested would be 3$6 \times 10^{-5} \mathrm{mmol} / \mathrm{g} /$ day, which would be equivalent to $1.8-$ $3.6 \mathrm{mmol} /$ day for an average-weight $(60 \mathrm{~kg})$ human; therefore, this may be the dose needed to achieve biological effects in the clinical setting. Consistent with this speculation, it was reported that drinking $1.5 \mathrm{~L}_{\text {of }} \mathrm{H}_{2}$ enriched water (approximately $0.6 \mathrm{mM}$ ) daily for 8 weeks (that is, $0.9 \mathrm{mmol}$ of $\mathrm{H}_{2}$ ingested daily) reduced urinary oxidative product (malondialdehyde) and increased antioxidant (superoxide dismutase) levels in subjects with metabolic syndrome [72]. Accordingly, it is thought that at least this dosage may be required to elicit any clinical effect in humans.

\section{$\mathrm{H}_{\mathbf{2}}$ application for hemodialysis treatment $\mathrm{H}_{2}$-enriched water rendered by water electrolysis and biological effects}

With the recent progress of $\mathrm{H}_{2}$ science, therapeutic application of $\mathrm{H}_{2}$ has become a clinical challenge [73, 74]. However, practical aspects of how to deliver $\mathrm{H}_{2}$ in a safe and stable manner at the bedside have been a concern. In light of this, we have focused on a water electrolysis technique (Fig. 2).

Water electrolysis gives rise to $\mathrm{H}_{2}$ enrichment near the electrolysis chamber cathode. The size of an $\mathrm{H}_{2}$ bubble is thought to be less than $1 \mu \mathrm{m}$ in diameter [75], and because of this extremely small size, the half-life of stable $\mathrm{H}_{2}$ in water is approximately $12 \mathrm{~h}$. The $\mathrm{H}_{2}$ concentration in water depends on the intensity of the electrolysis; it is 


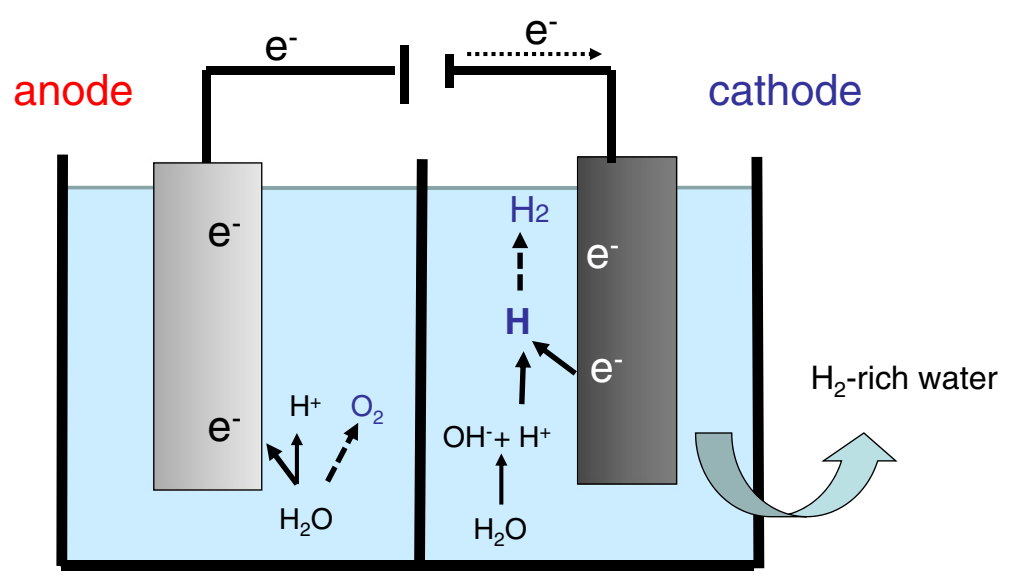

Fig. 2 Principle of water electrolysis and chemical properties of electrolyzed water at the cathode side. Water electrolysis supplies electrons to the cathode side. Electrons at the cathode surface react with hydrogen ions $(\mathrm{H}+)$ in water to produce theoretical intermediate hydrogen atoms and the final product, i.e., hydrogen molecules $\left(\mathrm{H}_{2}\right)$, by a chemical process. Chemical properties of electrolyzed water are characterized by alkalinity and the presence of dissolved hydrogen molecules $\left(\mathrm{H}_{2}\right)$

possible to deliver water having $0.3-0.5 \mathrm{mg} / \mathrm{L}$ using presently available commercial electrolysis equipment $[58,59]$. Shirahata et al. [76] demonstrated the unique chemical characteristics of electrolyzed water near the cathode, such as its antioxidant capacity. The hypoxanthinexanthine oxidase system generates superoxide anions $\left(\mathrm{O}_{2}^{-}\right)$. In $\mathrm{H}_{2}$-enriched electrolyzed water, concentrations of $\mathrm{O}_{2}^{-}$ and, furthermore, of hydrogen peroxide $\left(\mathrm{H}_{2} \mathrm{O}_{2}\right)$ are lower when compared with control water. DNA breakage in a mixture of $\mathrm{Cu}(\mathrm{II})$ and ascorbic acid was suppressed by this water. Considered together, these results indicate that $\mathrm{H}_{2}$ enriched water rendered by an electrolysis system could elicit chemical reactions in a similar way to the $\mathrm{H}_{2}$ molecule, as described above.

Studies designed to test the biological activity of electrolyzed water have demonstrated tumor antiproliferative effects [77-79] and antidiabetic actions in a diabetic model by amelioration of beta cell oxidative injury [80-82]. Drinking enriched water ad libitum ameliorated disuse muscular atrophy after paralysis in rats [58] and protected against cardiac and kidney fibrosis by ischemic/reperfusion of kidney [59] and aging [83] in Dahl SS rats. Furthermore, chronic ad libitum drinking could reduce lipopolysaccharide-induced neuroinflammation by downregulation of TNF- $\alpha$ and upregulation of IL-10 in the brain, to promote recovery from sickness behavior in mice [84].

\section{Manufacture and delivery of $\mathrm{H}_{2}$ dialysate using water electrolysis technique}

The clinical application of electrolyzed water rendered at the cathode as HD therapy was reported in 2003 by Hung et al. in Taiwan [24]. The primary system employed in that report and our present study is shown in Fig. 3. In studies from the Taiwanese group, after 6 months of regular treatments with the HD solution manufactured in this manner, reductions in serum IL-6 and CRP levels were seen in 26 patients enrolled in the study [24]. Furthermore, reductions in levels of methemoglobin [25] and apoptotic lymphocytes [26] were reported in subsequent studies. These results indicated that clinical application of electrolyzed water could have some clinical impact. However, the precise nature of the involvement of $\mathrm{H}_{2}$ in these studies has remained unclear, since the concept of $\mathrm{H}_{2}$ therapy was not considered at that time.

This issue was clarified by our recent study [29]. The amount of $\mathrm{H}_{2}$ obtained using this technique depends primarily on the intensity of water electrolysis; however, the maximum levels of $\mathrm{H}_{2}$ are limited to approximately $200 \mathrm{ppb}$ in the original system because of the increase in alkalinity with intensification of electrolysis. As shown in Fig. 3, $\mathrm{H}_{2}$ levels after electrolysis exceeded $200 \mathrm{ppb}$, followed by a decline during reverse osmosis to $50 \mathrm{ppb}$ in the final HD solution. Since the $\mathrm{H}_{2}$ in the HD solution moves completely into blood through the dialyzer membrane, the delivered dose depends on the flow rate of the solution. Given that the blood and dialysis solution flow remain constant, e.g., $200 \mathrm{ml} / \mathrm{min}$ for the blood flow, and $500 \mathrm{ml} / \mathrm{min}$ for the solution flow, it would be possible to achieve a 1-3 $\mathrm{mmol}_{2}$ load in a single HD session.

\section{Clinical experiences of electrolyzed HD and mechanistic hypothesis of clinical effects by $\mathrm{H}_{2}$ delivery Reported clinical signs and symptoms delivered by $\mathrm{H}_{2}$-enriched $H D$ solution and possible mechanistic role of $\mathrm{H}_{2}$ delivery \\ Since the start of collaborative project over development} of novel hemodialysis system between Nihon Trim Co., Ltd. and Tohoku University Graduate School of Medicine at 2007, case series to suggest clinical significance 


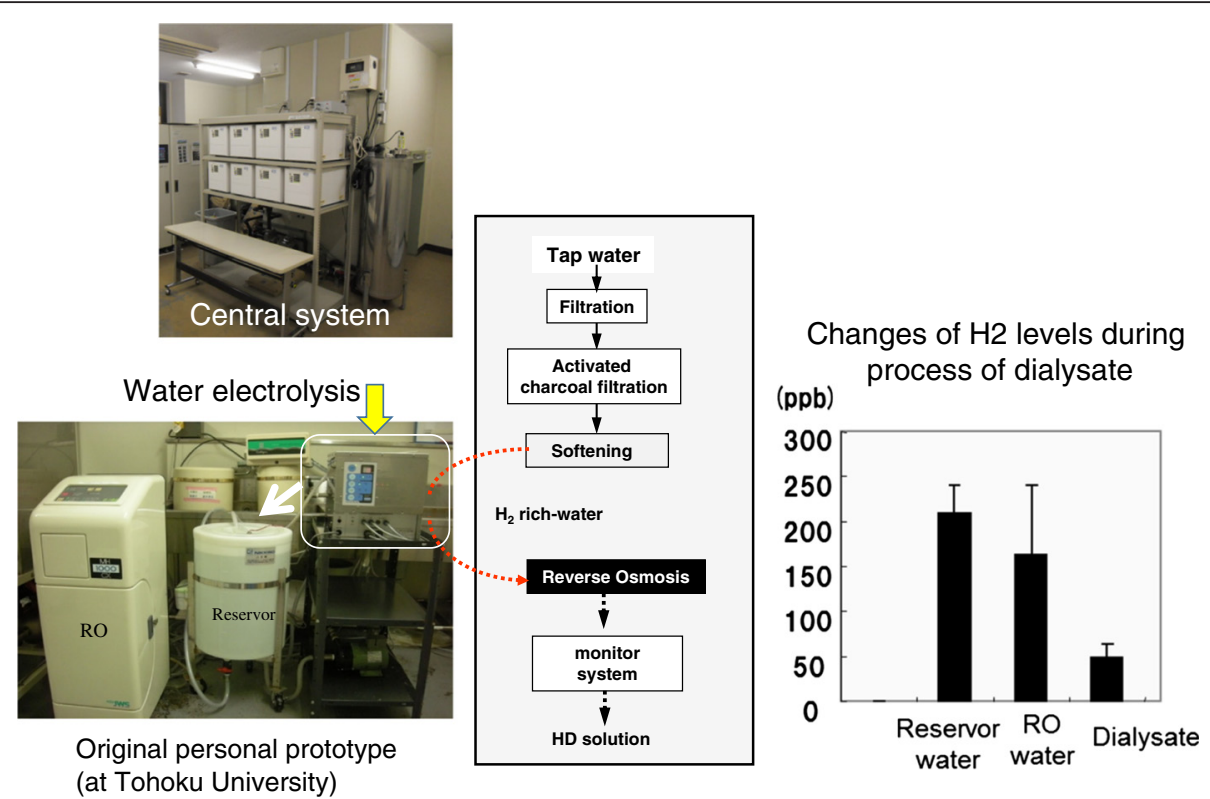

Fig. 3 Original manufacturing process of hemodialysis solution. Tap water is processed by filtration, activated charcoal filtration, and softening, followed by water electrolysis to deliver $\mathrm{H}_{2}$-rich water for reverse osmosis. There is a progressive decline in $\mathrm{H}_{2}$ levels by this process, and the final $\mathrm{H}_{2}$ content in dialysate solution is approximately $50 \mathrm{ppb}$ (right figure). Images show the original personal prototype of the electrolyzed HD system with a single water electrolyzer (left below) and the recent central system for multiple patients that incorporates multiple electrolyzers (left upper)

of this system have been accumulating. We and our collaborators have so far observed various clinical benefits in patients receiving this therapy $[29,85] . \mathrm{H}_{2}$-enriched HD solution corrected intra- and inter-dialytic high blood pressure (Fig. $4 \mathrm{a}-\mathrm{c}$ ), prevented blood flow reduction by function of dialysis, and increased skin temperature in cases with peripheral arteriosclerosis (Fig. 5a, b), enhanced wound healing in a case with ischemic lower limb lesion (Fig. 5c).

The role of $\mathrm{H}_{2}$-enriched $\mathrm{HD}$ solution in these effects has remained speculative; however, it seems clear that the delivery of $\mathrm{H}_{2}$ during the $\mathrm{HD}$ session is involved with the mechanism. There is a close relationship between endothelial dysfunction and oxidative stress. Generation of oxygen radicals in dialysis patients, e.g., iron infusion and uremic oxidants, such as indolyl sulfate, could disturb endothelium-dependent vascular relaxation $[86,87]$ and accelerate atherosclerosis by enhancing expression of cell adhesion molecules, such as intercellular adhesion molecule-1 (ICAM-1) and vascular cell adhesion molecule-1 (VCAM1) of endothelium [88]. During the process of NOS uncoupling, a characteristic feature of patients with chronic kidney disease, the superoxide anion reacts with nitric oxide to inactivate the bioactivity of $\mathrm{NO}$ and to generate peroxynitrite, a potent vasoconstrictive substance [89]. These processes could be involved in the pathological mechanism of increased blood pressure and decreased lower limb peripheral blood flow, which result in exaggeration of arteriosclerosis obliterans (ASO) and uncontrolled hypertension. Thus, we speculate that $\mathrm{H}_{2}$ as antioxidant may have suppressed these pathological processes.

There is also a close relationship between enhanced oxidative stress/inflammation and clinical symptoms which associate with dialysis treatment. Those include dialysis hypotension, fatigue, and pruritus. Interestingly, we have observed substantial effects of $\mathrm{H}_{2}$-enriched $\mathrm{HD}$ solution on ameliorating dialysis-related hypotension and subjective symptoms of dialysis-related fatigue and uremic pruritus.

Dialysis hypotension, which is defined as intra-dialytic hypotension, is a critical indicator of poor outcome. Frequent episodes of hypotension may induce a noxious inflammatory response mediated by the oxidative stress $[90,91]$. It is supposed that abrupt fall in blood pressure accompanies systemic pathological condition which mimic acute ischemia reperfusion, inducing inflammatory type M1 macrophage activation [92]. Furthermore, elevated levels of serum IL-6 in patients with fatigue [93], and skin micro-inflammation in patients with uremic pruritus $[94,95]$, have been reported. Therefore, it is possible to speculate that $\mathrm{H}_{2}$ may interact with the underlying pathology of enhanced oxidative stress or inflammation by inactivating oxygen radicals, leading to amelioration of clinical conditions.

\section{Mechanistic hypothesis of clinical effects delivered by $\mathrm{H}_{2}-$ enriched $H D$ solution}

As already mentioned, the primary action involved in $\mathrm{H}_{2}$ protection from organ injury is thought to quench toxic 


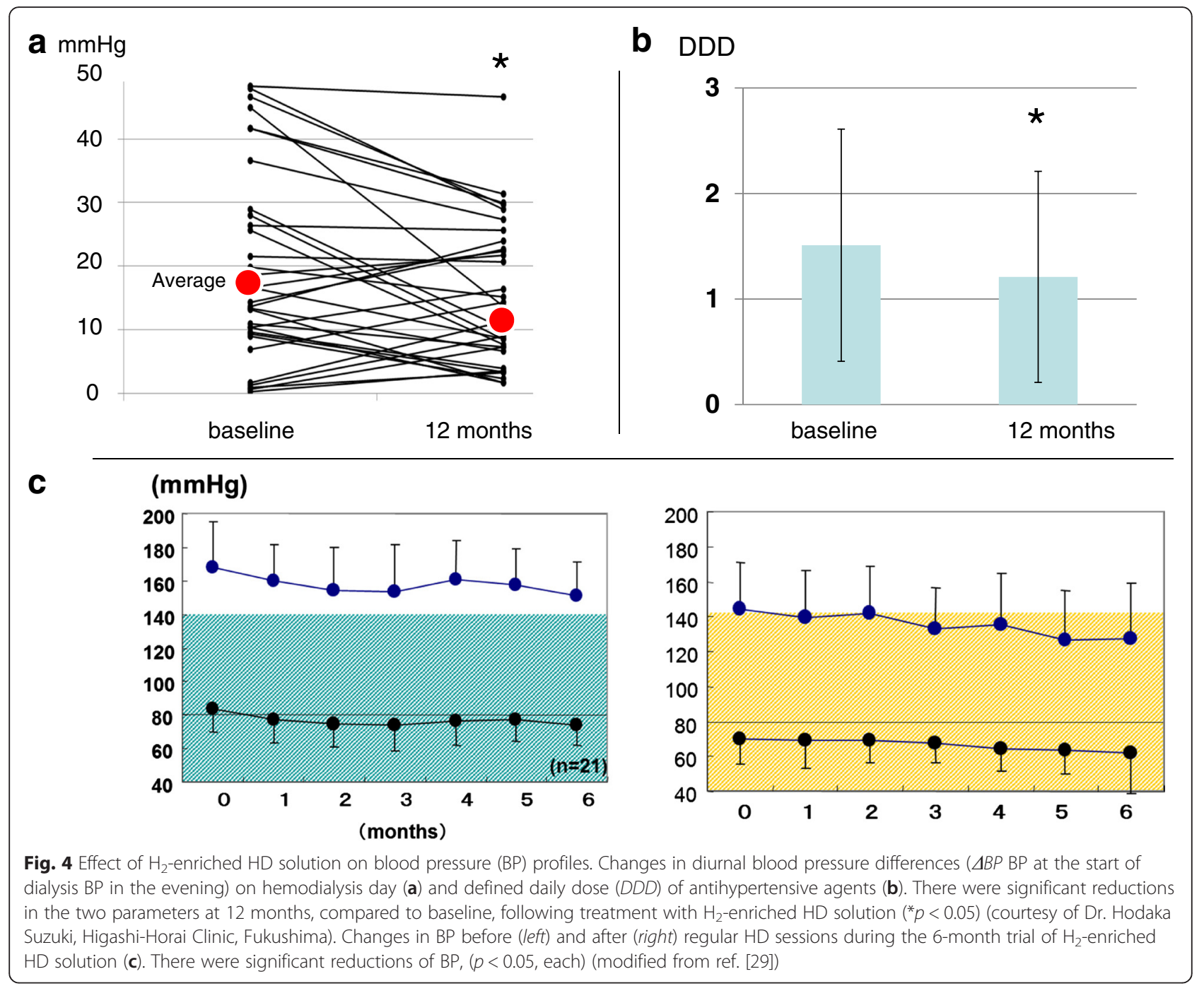

radicals, such as excess superoxide anion and hydroxyl radical (Fig. 6). Nevertheless, the observed clinical effects were not confined to the time period of HD sessions of three times a week. Upon the fact that elevated $\mathrm{H}_{2}$ level during HD returns to baseline as soon as the HD stops, it is therefore difficult to expect prolonged clinical effects from the chemical point of view of the $\mathrm{H}_{2}$ molecule. Thus, we think additional mechanism(s) should be indicated in mediating the clinical effect of $\mathrm{H}_{2}$ enriched solution.

The redox state is determined by the balance between the extent of oxidative stress and the activity of antioxidative mechanisms. This is crucially influenced during the course of an HD session, since there is an enhancement of free radical generation from polymorphonuclear cells during HD [16], which indicates excess apoptosis and disturbance of the physiological function of these cell populations. High plasma MPO, released from injured neutrophils, is an independent risk factor for patient survival [96]. In chronic kidney disease, monocyte heterogeneity is widely acknowledged, and a growing body of circumstantial evidence suggests that intermediate monocytes $(\mathrm{CD} 14(++) \mathrm{CD} 16(+))$ is predisposed to secrete pro-inflammatory cytokines [97] and that polarization of monocyte and macrophage is disturbed, e.g., polarization of becoming dominant macrophages is impaired; enhanced pro-inflammatory (M1); and impaired anti-inflammatory (M2) phenotypes, which corresponds to the progression of inflammation $[98,99]$.

Considering these facts, it is important to suppress excess immune cell injury within the dialyzer, while preserving normal cellular functions of these circulating cells, which exaggerate the inflammation-prone pathological process of disorders such as atherosclerotic and ischemic lesions of the vasculature.

$\mathrm{H}_{2}$-enriched solution could benefit patients on HD in this regard. There is an increase of reduced/oxidized albumin ratio by single $\mathrm{HD}$ session using $\mathrm{H}_{2}$-enriched 


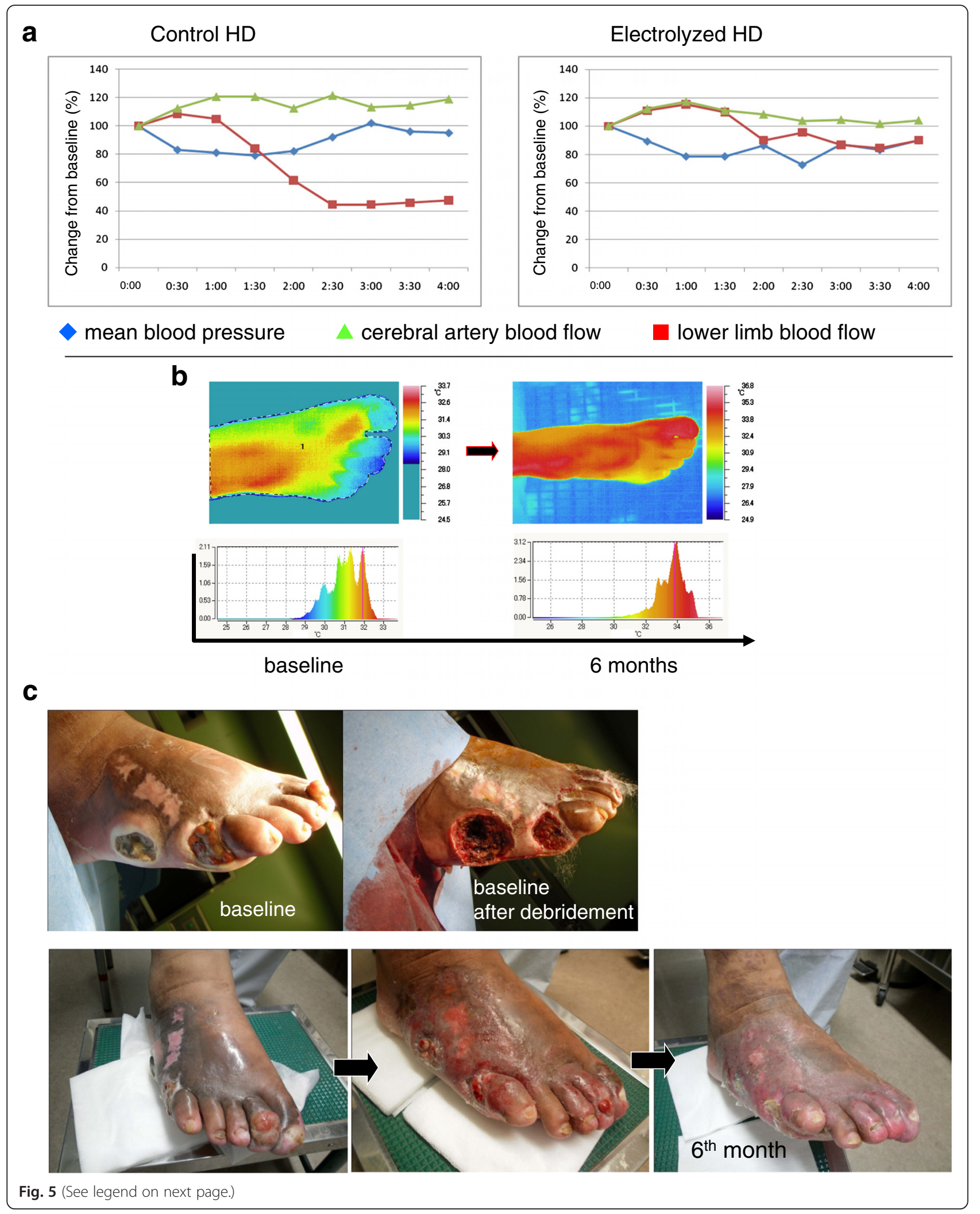


(See figure on previous page.)

Fig. 5 Effect of $\mathrm{H}_{2}$-enriched HD solution on changes in blood flow and skin temperature of the lower limb: a clinical case. A case with progressive decline in lower limb blood flow during regular HD session (left); the decline was suppressed by introduction of $\mathrm{H}_{2}$-enriched $\mathrm{HD}$ solution (right) (courtesy of Dr. Kazumasa Usami, Taigenkai Hospital, Ichinomiya). a A case showing improved aggregated lower limb coldness with uncontrollable ulceration on stubbed toe after the introduction of $\mathrm{H}_{2}$-enriched $\mathrm{HD}$ solution ( 6 months). $\mathbf{b} \mathrm{A}$ case showing improved intractable lower limb ulceration due to obstructive arteriosclerosis after the introduction of $\mathrm{H}_{2}$-enriched HD solution (6 months) (b, c courtesy of Dr. Hirofumi Nakano, Kashima Hospital, Iwaki)

solution [100]. In an ex vivo study, there was an increased oxidative injury of polymorphonuclear leukocytes during HD, but the injury was reduced with the use of $\mathrm{H}_{2}$-enriched solution [27]. Furthermore, available data indicated that induction of inflammatory M1 macrophages is suppressed by $\mathrm{H}_{2}$ [101]. Taken together, we speculate that induction of pro-inflammatory conditioning of immune cells which enhance oxidative stress during the HD session plays a crucial role for the dialysisrelated adverse effects and that amelioration of injured circulating immune cells by $\mathrm{H}_{2}$-enriched solution could

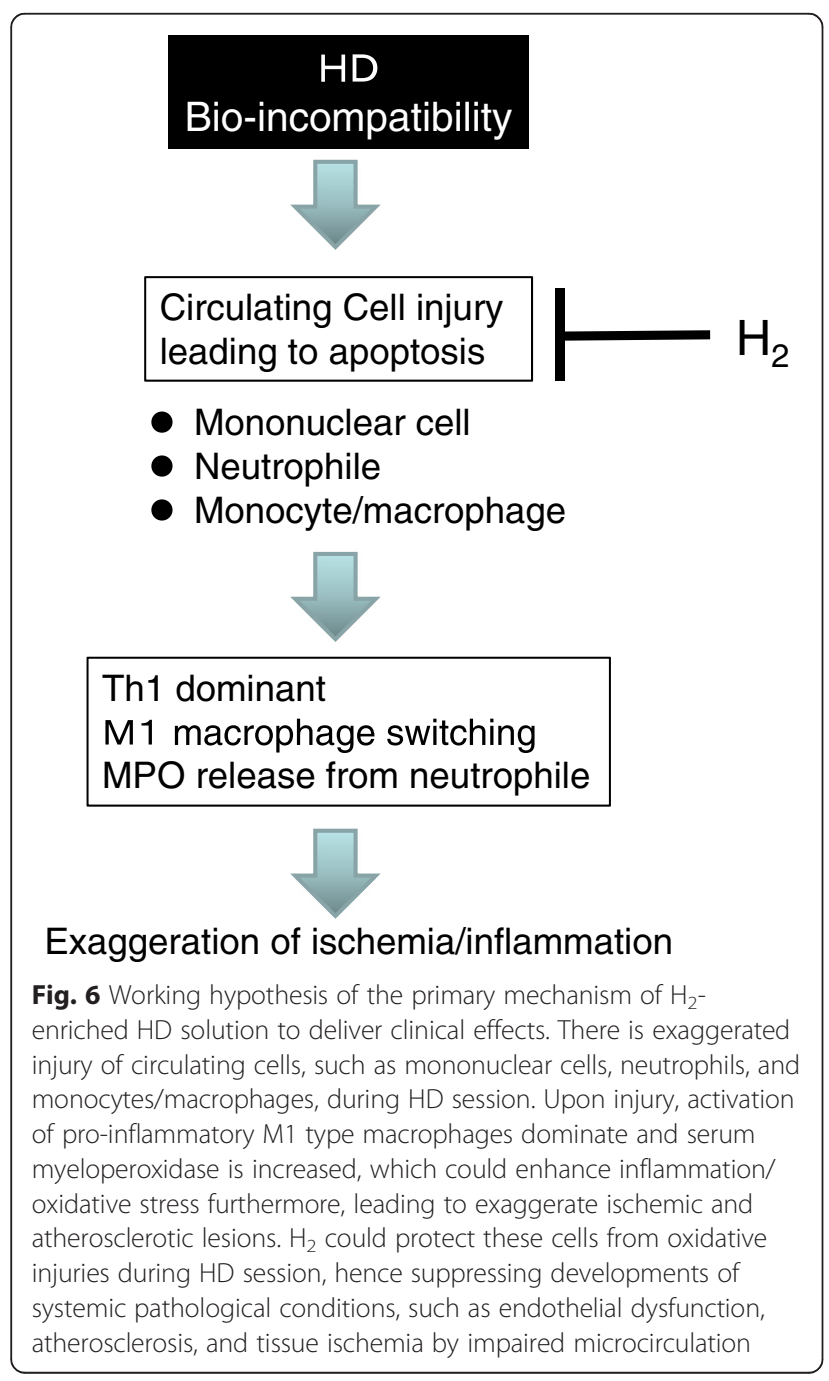

contribute to the appearance of clinical effects. This point needs to be further elucidated in future studies.

\section{Future directions for $\mathrm{H}_{2}$ therapy in chronic dialysis patients}

Thus far, clinical studies of $\mathrm{H}_{2}$ therapy have been limited; however, therapeutic intervention with $\mathrm{H}_{2}$ has great potential to benefit patients on chronic dialysis treatment. Comorbidities like renal anemia, malnutrition, vascular calcification, and dialysis hypotension are potential targets for $\mathrm{H}_{2}$ therapy, since all are associated with enhanced oxidative stress. Currently, whether uremic micro-inflammation is a cause of erythropoietin-resistant renal anemia is a matter of debate [102, 103]. Inflammation stimulates hepcidine production, which suppresses iron utilization and worsens renal anemia. Malnutrition observed during long-term dialysis treatment often accompanies inflammation, as the so-called malnutritioninflammation atherosclerosis (MIA) syndrome [104]. Development of vascular calcification is connected with the transformation of vascular smooth muscle cells, in which oxidative stress plays a crucial role $[105,106]$.

Further studies designed to ascertain the clinical effect of $\mathrm{H}_{2}$ on these disorders are warranted. Currently, the

\section{$\mathrm{H}_{2}$ level Clinical effect

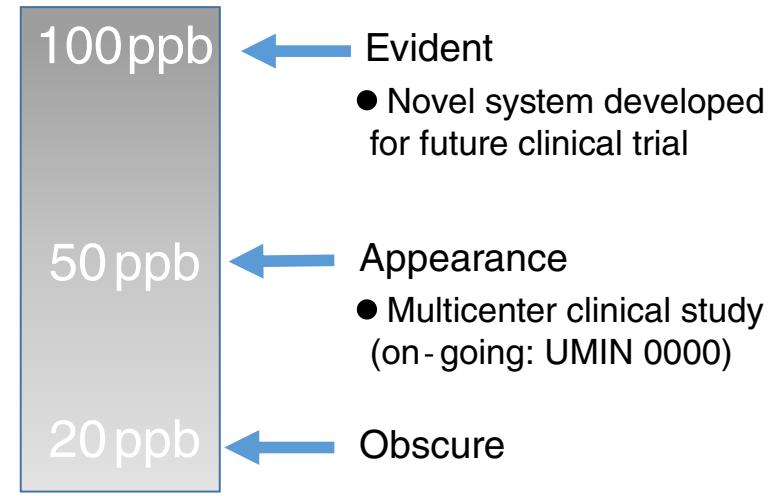

Fig. 7 Possible relationship between dialysate $\mathrm{H}_{2}$ level and clinical effect. Clinical studies conducted using dialysate solution of approximately $50 \mathrm{ppb} \mathrm{H}_{2}$ showed some clinical effects (UMIN000004857). These effects become more evident at $>100 \mathrm{ppb} \mathrm{H}_{2}$, were diminished at lower levels, and become obscure at $<20 \mathrm{ppb}$. A novel water electrolyzer capable of supplying $\mathrm{HD}$ solutions with $\mathrm{H}_{2}$ exceeding 200 ppb has been developed for assessment in a future clinical trial 
optimal effective clinical $\mathrm{H}_{2}$ dose is not known. Moreover, the existence of a dose-response relationship between the amount of $\mathrm{H}_{2}$ delivered in each HD session and clinical benefit remains unclear (Fig. 7). This issue needs to be addressed in order to fully explore the clinical applications of $\mathrm{H}_{2}$ in future trials.

\section{Conclusions}

Recent studies have revealed that $\mathrm{H}_{2}$ has a unique biological capacity to act as an antioxidative and antiinflammatory substance. In light of accumulating evidence from animal studies showing protective effects against organ damage during ischemia and inflammation, development of $\mathrm{H}_{2}$ treatments for $\mathrm{HD}$ patients has become a challenging clinical goal. An HD system utilizing a water electrolysis technique that renders large amounts of $\mathrm{H}_{2}$-enriched water has been developed. Accumulating findings indicate that the use of an $\mathrm{H}_{2}$ enriched solution may prove to be a novel approach to ameliorate dialysis-related complications.

\section{Competing interests}

MN and SI have no competing interests. SK is an employee of Trim Med Institute.

\section{Authors' contributions}

MN surveyed the published manuscript and finalized this review. SK helped to draft the manuscript and to collect the clinical data of the hemodialysis applying electrolyzed water for this review. SI organized the comprehensive study project of the clinical use of electrolyzed water and gave comments to MN and SI. All authors read and approved the final manuscript.

\section{Acknowledgements}

The authors thank to Drs Hirofumi Nakano, Hodaka Suzuki, and Kazumasa Usami for providing their valuable clinical data regarding the electrolyzed water-hemodialysis in drafting this manuscript.

\section{Author details}

'Department of Nephrology and Hypertension, Fukushima Medical University, Hikarigaoka 1, Fukushima City 960-1295, Japan. ${ }^{2}$ United Centers for Advanced Research and Translational Medicine, Center for Advanced and Integrated Renal Science, Tohoku University, Sendai, Japan. ${ }^{3}$ Trim Medical Institute Co., Ltd., Osaka, Japan. ${ }^{4}$ Division of Nephrology, Endocrinology and Vascular Medicine, Tohoku University Graduate School of Medicine, Sendai, Japan

Received: 4 February 2016 Accepted: 22 March 2016

Published online: 22 June 2016

\section{References}

1. Himmelfarb J, Stenvinkel P, Ikizler TA, Hakim RM. The elephant in uremia: oxidant stress as a unifying concept of cardiovascular disease in uremia. Kidney Int. 2002;62(5):1524-38. Review.

2. Terawaki H, Era S, Nakayama M, Hosoya T. Decrease in reduced-form albumin among chronic kidney disease patients: new insights in cardiovascular complications. Ther Apher Dial. 2011;15(2):156-60.

3. Terawaki H, Takada Y, Era S, Funakoshi Y, Nakayama K, Nakayama M, et al. The redox state of albumin and serious cardiovascular incidence in hemodialysis patients. Ther Apher Dial. 2010;14(5):465-71.

4. Terawaki H, Nakayama K, Matsuyama Y, Nakayama M, Sato T, Hosoya T, et al. Dialyzable uremic solutes contribute to enhanced oxidation of serum albumin in regular hemodialysis patients. Blood Purif. 2007;25(3):274-9.

5. Niwa T. Indoxyl sulfate is a nephro-vascular toxin. J Ren Nutr. 2010;20(5 Suppl):S2-6.
6. Gawlowski T, Stratmann B, Stirban AO, et al. AGEs and methylglyoxal induce apoptosis and expression of $\mathrm{Mac}^{-1}$ on neutrophils resulting in plateletneutrophil aggregation. Thromb Res. 2007;121:117-26.

7. Witko-Sarsat V, Gausson V, Nguyen AT, Touam M, Drüeke T, Santangelo F, et al. AOPP-induced activation of human neutrophil and monocyte oxidative metabolism: a potential target for $\mathrm{N}$-acetylcysteine treatment in dialysis patients. Kidney Int. 2003;64(1):82-91.

8. Nakayama K, Nakayama M, Iwabuchi M, Terawaki H, Sato T, Kohno M, et al. Plasma alpha-oxoaldehyde levels in diabetic and nondiabetic chronic kidney disease patients. Am J Nephrol. 2008;28(6):871-8.

9. Nakayama M, Nakayama K, Zhu WJ, Shirota Y, Terawaki H, Sato T, et al. Polymorphonuclear leukocyte injury by methylglyoxal and hydrogen peroxide: a possible pathological role for enhanced oxidative stress in chronic kidney disease. Nephrol Dial Transplant. 2008;23(10):3096-102.

10. Toyohara T, Suzuki T, Morimoto R, Akiyama Y, Souma T, Shiwaku HO, et al. SLCO4C1 transporter eliminates uremic toxins and attenuates hypertension and renal inflammation. J Am Soc Nephrol. 2009;20(12):2546-55.

11. Sela S, Shurtz-Swirski R, Cohen-Mazor M, Mazor R, Chezar J, Shapiro G, et al. Primed peripheral polymorphonuclear leukocyte: a culprit underlying chronic low-grade inflammation and systemic oxidative stress in chronic kidney disease. J Am Soc Nephrol. 2005:16:2431-8.

12. Ward RA, McLeish KR. Polymorphonuclear leukocyte oxidative burst is enhanced in patients with chronic renal insufficiency. J Am Soc Nephrol. 1995;5:1697-702.

13. Maruyama $Y$, Lindholm B, Stenvinkel P. Inflammation and oxidative stress in ESRD — the role of myeloperoxidase. J Nephrol. 2004;17:S72-6.

14. Perna AF, Luciano MG, Ingrosso D, Pulzella P, Sepe I, Lanza D, et al. Hydrogen sulphide-generating pathways in haemodialysis patients: a study on relevant metabolites and transcriptional regulation of genes encoding for key enzymes. Nephrol Dial Transplant. 2009;24(12):3756-63.

15. Kim HJ, Vaziri ND. Contribution of impaired Nrf2-Keap1 pathway to oxidative stress and inflammation in chronic renal failure. Am J Physiol Renal Physiol. 2010;298(3):F662-71.

16. Yoon JW, Pahl MV, Vaziri ND. Spontaneous leukocyte activation and oxygen-free radical generation in end-stage renal disease. Kidney Int. 2007;71(2):167-72

17. Nakayama K, Terawaki H, Nakayama M, Iwabuchi M, Sato T, Ito S. Reduction of serum antioxidative capacity during hemodialysis. Clin Exp Nephrol. 2007;11(3):218-24.

18. Libetta C, Zucchi M, Gori E, Sepe V, Galli F, Meloni F, et al. Vitamin E-loaded dialyzer resets PBMC-operated cytokine network in dialysis patients. Kidney Int. 2004;65(4):1473-81.

19. Mann JF, Lonn EM, Yi Q, Gerstein HC, Hoogwerf BJ, Pogue J, et al. Effects of vitamin $\mathrm{E}$ on cardiovascular outcomes in people with mild-to-moderate renal insufficiency: results of the HOPE study. Kidney Int. 2004;65(4):1375-80.

20. Boaz M, Smetana S, Weinstein T, Matas Z, Gafter U, laina A, et al. Secondary prevention with antioxidants of cardiovascular disease in end stage renal disease (SPACE): randomised placebo-controlled trial. Lancet. 2000;356(9237):1213-8.

21. Tepel M, van der Giet M, Statz M, Jankowski J, Zidek W. The antioxidant acetylcysteine reduces cardiovascular events in patients with end-stage renal failure: a randomized, controlled trial. Circulation. 2003;107(7):992-5.

22. Ohsawa I, Ishikawa M, Takahashi K, Watanabe M, Nishimaki K, Yamagata K, et al. Hydrogen acts as a therapeutic antioxidant by selectively reducing cytotoxic oxygen radicals. Nat Med. 2007:13(6):688-94.

23. Ohta S. Recent progress toward hydrogen medicine: potential of molecular hydrogen for preventive and therapeutic applications. Curr Pharm Des. 2011;17(22):2241-52

24. Huang KC, Yang CC, Lee KT, Chien CT. Reduced hemodialysis-induced oxidative stress in end-stage renal disease patients by electrolyzed reduced water. Kidney Int. 2003;64(2):704-14.

25. Huang KC, Yang CC, Hsu SP, Lee KT, Liu HW, Morisawa S, et al. Electrolyzedreduced water reduced hemodialysis-induced erythrocyte impairment in end-stage renal disease patients. Kidney Int. 2006;70(2):391-8.

26. Huang KC, Hsu SP, Yang CC, Ou-Yang P, Lee KT, Morisawa S, et al. Electrolysed-reduced water dialysate improves T-cell damage in end-stage renal disease patients with chronic haemodialysis. Nephrol Dial Transplant. 2010;25(8):2730-7.

27. Nakayama M, Kabayama S, Terawaki H, Nakayama K, Kato K, Sato T, et al. Less-oxidative hemodialysis solution rendered by cathode-side application of electrolyzed water. Hemodial Int. 2007;11:322-7. 
28. Nakayama M, Kabayama S, Nakano H, Zhu WJ, Terawaki H, Nakayama K, et al. Biological effects of electrolyzed water in hemodialysis. Nephron Clin Pract. 2009;112:c9-15.

29. Nakayama M, Nakano H, Hamada H, Itami N, Nakazawa R, Ito S. A novel bioactive haemodialysis system using dissolved dihydrogen $(\mathrm{H} 2)$ produced by water electrolysis: a clinical trial. Nephrol Dial Transplant. 2010;25:3026-33.

30. Fukuda K, Asoh S, Ishikawa M, Yamamoto Y, Ohsawa I, Ohta S. Inhalation of hydrogen gas suppresses hepatic injury caused by ischemia/reperfusion through reducing oxidative stress. Biochem Biophys Res Commun. 2007;361(3):670-4.

31. Buchholz BM, Kaczorowski DJ, Sugimoto R, Yang R, Wang Y, Billiar TR, et al. Hydrogen inhalation ameliorates oxidative stress in transplantation induced intestinal graft injury. Am J Transplant. 2008;8(10):2015-24.

32. Ohsawa I, Nishimaki K, Yamagata K, Ishikawa M, Ohta S. Consumption of hydrogen water prevents atherosclerosis in apolipoprotein E knockout mice. Biochem Biophys Res Commun. 2008;377(4):1195-8.

33. Cai J, Kang Z, Liu WW, Luo X, Qiang S, Zhang JH, et al. Hydrogen therapy reduces apoptosis in neonatal hypoxia-ischemia rat model. Neurosci Lett. 2008;441(2):167-72.

34. Hayashida K, Sano M, Ohsawa I, Shinmura K, Tamaki K, Kimura K, et al. Inhalation of hydrogen gas reduces infarct size in the rat model of myocardial ischemia-reperfusion injury. Biochem Biophys Res Commun. 2008;373(1):30-5.

35. Sato Y, Kajiyama S, Amano A, Kondo Y, Sasaki T, Handa S, et al. Hydrogenrich pure water prevents superoxide formation in brain slices of vitamin C-depleted SMP30/GNL knockout mice. Biochem Biophys Res Commun. 2008;375(3):346-50.

36. Fu Y, Ito M, Fujita $Y$, Ito M, Ichihara M, Masuda A, et al. Molecular hydrogen is protective against 6-hydroxydopamine-induced nigrostriatal degeneration in a rat model of Parkinson's disease. Neurosci Lett. 2009:453(2):81-5.

37. Nakashima-Kamimura N, Mori T, Ohsawa I, Asoh S, Ohta S. Molecular hydrogen alleviates nephrotoxicity induced by an anti-cancer drug cisplatin without compromising anti-tumor activity in mice. Cancer Chemother Pharmacol. 2009;64(4):753-61.

38. Nagata K, Nakashima-Kamimura N, Mikami T, Ohsawa I, Ohta S. Consumption of molecular hydrogen prevents the stress-induced impairments in hippocampus-dependent learning tasks during chronic physical restraint in mice. Neuropsychopharmacology. 2009;34(2):501-8.

39. Cai J, Kang Z, Liu K, Liu W, Li R, Zhang JH, et al. Neuroprotective effects of hydrogen saline in neonatal hypoxia-ischemia rat model. Brain Res. 2009; 1256:129-37.

40. Fujita K, Seike T, Yutsudo N, Ohno M, Yamada H, Yamaguchi H, et al. Hydrogen in drinking water reduces dopaminergic neuronal loss in the 1-methyl-4-phenyl-1,2,3,6-tetrahydropyridine mouse model of Parkinson's disease. PLoS One. 2009;4(9):e7247.

41. Oharazawa $H$, Igarashi $T$, Yokota T, Fujii $H$, Suzuki $H$, Machide $M$, et al. Protection of the retina by rapid diffusion of hydrogen: administration of hydrogen-loaded eye drops in retinal ischemia-reperfusion injury. Invest Ophthalmol Vis Sci. 2010;51(1):487-92

42. Li J, Wang C, Zhang JH, Cai JM, Cao YP, Sun XJ. Hydrogen-rich saline improves memory function in a rat model of amyloid-beta-induced Alzheimer's disease by reduction of oxidative stress. Brain Res. 2010;1328:152-61.

43. Zheng J, Liu K, Kang Z, Cai J, Liu W, Xu W, et al. Saturated hydrogen saline protects the lung against oxygen toxicity. Undersea Hyperb Med. 2010;37(3):185-92

44. Kitamura A, Kobayashi S, Matsushita T, Fujinawa H, Murase K. Experimental verification of protective effect of hydrogen-rich water against cisplatininduced nephrotoxicity in rats using dynamic contrast-enhanced $\mathrm{CT}$. Br J Radiol. 2010;83(990):509-14.

45. Nakao A, Kaczorowski DJ, Wang Y, Cardinal JS, Buchholz BM, Sugimoto R, et al. Amelioration of rat cardiac cold ischemia/reperfusion injury with inhaled hydrogen or carbon monoxide, or both. J Heart Lung Transplant. 2010;29(5):544-53.

46. Huang CS, Kawamura T, Lee S, Tochigi N, Shigemura N, Buchholz BM, et al. Hydrogen inhalation ameliorates ventilator-induced lung injury. Crit Care. 2010;14(6):R234

47. Buchholz BM, Masutani $K$, Kawamura T, Peng $X$, Toyoda Y, Billiar TR, et al. Hydrogen-enriched preservation protects the isogeneic intestinal graft and amends recipient gastric function during transplantation. Transplantation. 2011;92(9):985-92
48. Cardinal JS, Zhan J, Wang Y, Sugimoto R, Tsung A, McCurry KR, et al. Oral hydrogen water prevents chronic allograft nephropathy in rats. Kidney Int. 2010;77(2):101-9.

49. Qian L, Cao F, Cui J, Huang Y, Zhou X, Liu S, et al. Radioprotective effect of hydrogen in cultured cells and mice. Free Radic Res. 2010;44(3):275-82.

50. Qian L, Cao F, Cui J, Wang Y, Huang Y, Chuai Y, et al. The potential cardioprotective effects of hydrogen in irradiated mice. J Radiat Res. 2010;51(6):741-7.

51. Kubota M, Shimmura S, Kubota S, Miyashita H, Kato N, Noda K, et al. Hydrogen and $\mathrm{N}$-acetyl-L-cysteine rescue oxidative stress-induced angiogenesis in a mouse corneal alkali-burn model. Invest Ophthalmol Vis Sci. 2011;52(1):427-33

52. Liu S, Liu K, Sun Q, Liu W, Xu W, Denoble P, et al. Consumption of hydrogen water reduces paraquat-induced acute lung injury in rats. J Biomed Biotechnol. 2011:2011:305086. Epub 2011 Jan 24

53. Kamimura N, Nishimaki K, Ohsawa I, Ohta S. Molecular hydrogen improves obesity and diabetes by inducing hepatic FGF21 and stimulating energy metabolism in db/db mice. Obesity (Silver Spring). 2011;19(7):1396-403.

54. Fang Y, Fu XJ, Gu C, Xu P, Wang Y, Yu WR, et al. Hydrogen-rich saline protects against acute lung injury induced by extensive burn in rat model. J Burn Care Res. 2011;32(3):e82-91.

55. Terasaki Y, Ohsawa I, Terasaki M, Takahashi M, Kunugi S, Dedong K, et al. Hydrogen therapy attenuates irradiation-induced lung damage by reducing oxidative stress. Am J Physiol Lung Cell Mol Physiol. 2011;301(4):L415-26.

56. Manaenko A, Lekic T, Ma Q, Ostrowski RP, Zhang JH, Tang J. Hydrogen inhalation is neuroprotective and improves functional outcomes in mice after intracerebral hemorrhage. Acta Neurochir Suppl. 2011;111:179-83.

57. Kasuyama K, Tomofuji T, Ekuni D, Tamaki N, Azuma T, Irie K, et al. Hydrogen-rich water attenuates experimental periodontitis in a rat model. J Clin Periodontol. 2011;38(12):1085-90.

58. Fujita R, Tanaka Y, Saihara Y, Yamakita M, Ando D, Koyama K. Effect of molecular hydrogen saturated alkaline electrolyzed water on disuse muscle atrophy in gastrocnemius muscle. J Physiol Anthropol. 2011;30(5):195-201.

59. Zhu WJ, Nakayama M, Mori T, Nakayama K, Katoh J, Murata Y, et al. Intake of water with high levels of dissolved hydrogen $\left(\mathrm{H}_{2}\right)$ suppresses ischemiainduced cardio-renal injury in Dahl salt-sensitive rats. Nephrol Dial Transplant. 2011;26(7):2112-8

60. Wang F, Yu G, Liu SY, Li JB, Wang JF, Bo LL, et al. Hydrogen-rich saline protects against renal ischemia/reperfusion injury in rats. J Surg Res. 2011;167(2):e339-44.

61. Kato S, Saitoh Y, Iwai K, Miwa N. Hydrogen-rich electrolyzed warm water represses wrinkle formation against UVA ray together with type-I collagen production and oxidative-stress diminishment in fibroblasts and cell-injury prevention in keratinocytes. J Photochem Photobiol B. 2012;106:24-33.

62. Nagatani K, Wada K, Takeuchi S, Kobayashi H, Uozumi Y, Otani N, et al. Effect of hydrogen gas on the survival rate of mice following global cerebral ischemia. Shock. 2012;37(6):645-52.

63. Zhan Y, Chen C, Suzuki H, Hu Q, Zhi X, Zhang JH. Hydrogen gas ameliorates oxidative stress in early brain injury after subarachnoid hemorrhage in rats. Crit Care Med. 2012;40(4):1291-6.

64. Ge P, Zhao J, Li S, Ding Y, Yang F, Luo Y. Inhalation of hydrogen gas attenuates cognitive impairment in transient cerebral ischemia via inhibition of oxidative stress. Neurol Res. 2012:34(2):187-94.

65. Tan M, Sun X, Guo L, Su C, Sun X, Xu Z. Hydrogen as additive of HTK solution fortifies myocardial preservation in grafts with prolonged cold ischemia. Int J Cardiol. 2013;167(2):383-90.

66. Qu J, Gan YN, Xie KL, Liu WB, Wang YF, Hei RY, et al. Inhalation of hydrogen gas attenuates ouabain-induced auditory neuropathy in gerbils. Acta Pharmacol Sin. 2012;33(4):445-51.

67. Zheng H, Yu YS. Chronic hydrogen-rich saline treatment attenuates vascular dysfunction in spontaneous hypertensive rats. Biochem Pharmacol. 2012:83(9):1269-77.

68. Chuai Y, Gao F, Li B, Zhao L, Qian L, Cao F, et al. Hydrogen-rich saline attenuates radiation-induced male germ cell loss in mice through reducing hydroxyl radicals. Biochem J. 2012;442(1):49-56.

69. Chuai Y, Shen J, Qian L, Wang Y, Huang Y, Gao F, et al. Hydrogen-rich saline protects spermatogenesis and hematopoiesis in irradiated BALB/C mice. Med Sci Monit. 2012;18(3):BR89-94.

70. Ohta S. Molecular hydrogen is a novel antioxidant to efficiently reduce oxidative stress with potential for the improvement of mitochondrial diseases. Biochim Biophys Acta. 2012;1820(5):586-94. Epub 2011 May 20. 
71. Chen H, Sun YP, Li Y, Liu WW, Xiang HG, Fan LY, et al. Hydrogen-rich saline ameliorates the severity of I-arginine-induced acute pancreatitis in rats. Biochem Biophys Res Commun. 2010;393(2):308-13.

72. Nakao A, Toyoda Y, Sharma P, Evans M, Guthrie N. Effectiveness of hydrogen rich water on antioxidant status of subjects with potential metabolic syndrome-an open label pilot study. J Clin Biochem Nutr. 2010;46(2):140-9.

73. George JF, Agarwal A. Hydrogen: another gas with therapeutic potential. Kidney Int. 2010;77(2):85-7.

74. Schoenfeld MP, Ansari RR, Zakrajsek JF, Billiar TR, Toyoda Y, Wink DA, et al. Hydrogen therapy may reduce the risks related to radiation-induced oxidative stress in space flight. Med Hypotheses. 2011;76(1):117-8.

75. Kikuchi K, Tanaka Y, Saihara Y, Maeda M, Kawamura M, Ogumi Z. Concentration of hydrogen nanobubbles in electrolyzed water. J Colloid Interface Sci. 2006;298(2):914-9.

76. Shirahata S, Kabayama S, Nakano M, Miura T, Kusumoto K, Gotoh M, et al. Electrolyzed-reduced water scavenges active oxygen species and protects DNA from oxidative damage. Biochem Biophys Res Commun. 1997;234(1):269-74.

77. Saitoh Y, Okayasu H, Xiao L, Harata Y, Miwa N. Neutral pH hydrogen-enriched electrolyzed water achieves tumor-preferential clonal growth inhibition over normal cells and tumor invasion inhibition concurrently with intracellular oxidant repression. Oncol Res. 2008;17(6):247-55.

78. Ye J, Li Y, Hamasaki T, Nakamichi N, Komatsu T, Kashiwagi T, et al. Inhibitory effect of electrolyzed reduced water on tumor angiogenesis. Biol Pharm Bull. 2008;31(1):19-26.

79. Tsai CF, Hsu YW, Chen WK, Ho YC, Lu FJ. Enhanced induction of mitochondrial damage and apoptosis in human leukemia HL-60 cells due to electrolyzed-reduced water and glutathione. Biosci Biotechnol Biochem. 2009;73(2):280-7.

80. Kim MJ, Kim HK. Anti-diabetic effects of electrolyzed reduced water in streptozotocin-induced and genetic diabetic mice. Life Sci. 2006;79(24): 2288-92. Epub 2006 Aug 2.

81. Kim MJ, Jung KH, Uhm YK, Leem KH, Kim HK. Preservative effect of electrolyzed reduced water on pancreatic beta-cell mass in diabetic $\mathrm{db} / \mathrm{db}$ mice. Biol Pharm Bull. 2007;30(2):234-6.

82. Li Y, Hamasaki T, Nakamichi N, Kashiwagi T, Komatsu T, Ye J, et al. Suppressive effects of electrolyzed reduced water on alloxan-induced apoptosis and type 1 diabetes mellitus. Cytotechnology. 2011;63(2):119-31.

83. Zhu WJ, Nakayama M, Mori T, Hao K, Terawaki H, Katoh J, et al. Amelioration of cardio-renal injury with aging in dahl salt-sensitive rats by $\mathrm{H} 2$-enriched electrolyzed water. Med Gas Res. 2013;3(1):26. doi:10.1186/2045-9912-3-26.

84. Spulber S, Edoff K, Hong L, Morisawa S, Shirahata S, Ceccatelli S. Molecular hydrogen reduces LPS-induced neuroinflammation and promotes recovery from sickness behaviour in mice. PLoS One. 2012;7(7):e42078.

85. Terawaki H, Nakano H, Zhu WJ, Nakayama M. Successful treatment of encapsulating peritoneal sclerosis by hemodialysis and peritoneal lavage using dialysate containing dissolved hydrogen. Perit Dial Int. 2015;35(1):107-12.

86. Bishu K, Agarwal R. Acute injury with intravenous iron and concerns regarding long-term safety. Clin J Am Soc Nephrol. 2006;1 Suppl 1:S19-23.

87. Ito S, Yoshida M. Protein-bound uremic toxins: new culprits of cardiovascular events in chronic kidney disease patients. Toxins (Basel). 2014;6(2):665-78.

88. Tumur Z, Shimizu H, Enomoto A, Miyazaki H, Niwa T. Indoxyl sulfate upregulates expression of icam-1 and mcp-1 by oxidative stress-induced nfkappab activation. Am J Nephrol. 2010;31:435-41.

89. Kietadisorn R, Juni RP, Moens AL. Tackling endothelial dysfunction by modulating NOS uncoupling: new insights into its pathogenesis and therapeutic possibilities. Am J Physiol Endocrinol Metab. 2012;302(5):E481-95.

90. Tomita M, Malhotra D, Dheenan S, Shapiro JI, Henrich WL, Santoro TJ. A potential role for immune activation in hemodialysis hypotension. Renal Failure. 2001;23:637-49.

91. Rostoker G, Griuncelli M, Loridon C, Bourlet T, Illouz E, Benmaadi A. Modulation of oxidative stress and microinflammatory status by colloids in refractory dialytic hypotension. BMC Nephrol. 2011;12:58.

92. Trial J, Cieslik KA, Haudek SB, Duerrschmid C, Entman ML. Th1/M1 conversion to th $2 / \mathrm{m} 2$ responses in models of inflammation lacking cell death stimulates maturation of monocyte precursors to fibroblasts. Front Immunol. 2013:4:287. doi:10.3389/fimmu.2013.00287. eCollection 2013.

93. Bossola M, Di Stasio E, Giungi S, Rosa F, Tazza L. Fatigue is associated with serum interleukin-6 levels and symptoms of depression in patients on chronic hemodialysis. J Pain Symptom Manage. 2015;49:578-85.
94. Virga G, Visentin I, La Milia V, Bonadonna A. Inflammation and pruritus in haemodialysis patients. Nephrol Dial Transplant. 2002;17:2164-9.

95. Kimmel M, Alscher DM, Dunst R, Braun N, Machleidt C, et al. The role of micro-inflammation in the pathogenesis of uraemic pruritus in haemodialysis patients. Nephrol Dial Transplant. 2006;21:749-55.

96. Wang AY, Lam CW, Chan IH, Wang M, Lui SF, Sanderson JE. Prognostic value of plasma myeloperoxidase in ESRD patients. Am J Kidney Dis. 2010;56(5):937-46.

97. Heine GH, Ortiz A, Massy ZA, Lindholm B, Wiecek A, Martínez-Castelao A, et al. Monocyte subpopulations and cardiovascular risk in chronic kidney disease. Nat Rev Nephrol. 2012;8(6):362-9.

98. Ravi S, Mitchell T, Kramer PA, Chacko B, Darley-Usmar VM. Mitochondria in monocytes and macrophages-implications for translational and basic research. Int J Biochem Cell Biol. 2014;53:202-7.

99. Li C, Ding XY, Xiang DM, Xu J, Huang XL, Hou FF, et al. Enhanced M1 and impaired M2 macrophage polarization and reduced mitochondrial biogenesis via inhibition of AMP kinase in chronic kidney disease. Cell Physiol Biochem. 2015;36(1):358-72.

100. Terawaki H, Zhu WJ, Matsuyama Y, Terada T, Takahashi Y, Sakurai K, et al. Effect of a hydrogen ( $\mathrm{H} 2)$-enriched solution on the albumin redox of hemodialysis patients. Hemodial Int. 2014;18(2):459-66.

101. Itoh T, Hamada N, Terazawa R, Ito M, Ohno K, Ichihara M, et al. Molecular hydrogen inhibits lipopolysaccharide/interferon $\gamma$-induced nitric oxide production through modulation of signal transduction in macrophages. Biochem Biophys Res Commun. 2011;411(1):143-9.

102. Hirayama A, Nagase S, Gotoh M, Ueda A, Ishizu T, Yoh K, et al. Reduced serum hydroxyl radical scavenging activity in erythropoietin therapy resistant renal anemia. Free Radic Res. 2002;36(11):1155-61.

103. Agarwal R. Iron, oxidative stress, and clinical outcomes. Pediatr Nephrol. 2008;23(8):1195-9.

104. Stenvinkel P, Alvestrand A. Inflammation in end-stage renal disease: sources, consequences, and therapy. Semin Dial. 2002;15(5):329-37.

105. Yamada S, Taniguchi M, Tokumoto M, Toyonaga J, Fujisaki K, Suehiro T, et al. The antioxidant tempol ameliorates arterial medial calcification in uremic rats: important role of oxidative stress in the pathogenesis of vascular calcification in chronic kidney disease. J Bone Miner Res. 2012;27(2):474-85.

106. Zhao MM, Xu MJ, Cai Y, Zhao G, Guan Y, Kong W, et al. Mitochondrial reactive oxygen species promote p65 nuclear translocation mediating high-phosphate-induced vascular calcification in vitro and in vivo. Kidney Int. 2011;79(10):1071-9.

\section{Submit your next manuscript to BioMed Central and we will help you at every step:}

- We accept pre-submission inquiries

- Our selector tool helps you to find the most relevant journal

- We provide round the clock customer support

- Convenient online submission

- Thorough peer review

- Inclusion in PubMed and all major indexing services

- Maximum visibility for your research

Submit your manuscript at www.biomedcentral.com/submit
C Biomed Central 